\title{
Development of Site-Specific PEGylated Granulocyte Colony Stimulating Factor With Prolonged Biological Activity
}

\author{
Monika Kumari, Girish Sahni and Sonal Datta* \\ Council of Scientific and Industrial Research, Institute of Microbial Technology, Chandigarh, India
}

Currently, amino-terminal PEGylated human granulocyte colony stimulating factor (huGCSF) is used to prevent and treat neutropenia. Although huG-CSF has been used as a drug for more than 20 years, it has three significant drawbacks: (i) it relies on PEG aldehyde for PEGylation of the alpha-amino group of the first amino acid, and this leads to non-specific PEGylation of the epsilon amino group of lysine residues

OPEN ACCESS

Edited by:

Chiranjib Chakraborty, Adamas University, India

Reviewed by:

Muhammad Nawaz, University of Gothenburg, Sweden

Manojit Bhattacharya,

Fakir Mohan University, India

${ }^{*}$ Correspondence:

Sonal Datta

sona@@imtech.res.in sdatta.sona/@gmail.com

Specialty section:

This article was submitted to Preclinical Cell and Gene Therapy,

a section of the journal Frontiers in Bioengineering and

Biotechnology

Received: 12 June 2020

Accepted: 07 October 2020

Published: 19 November 2020

Citation:

Kumari M, Sahni G and Datta S (2020) Development of Site-Specific

PEGylated Granulocyte Colony Stimulating Factor With Prolonged Biological Activity.

Front. Bioeng. Biotechnol. 8:572077. doi: 10.3389/fbioe.2020.572077 within the G-CSF; (ii) longer-acting G-CSF variants are desirable to reduce the risk of chemotherapy-associated neutropenia; and (iii) G-CSF cannot be administered on the day of chemotherapy. In an attempt to overcome the above drawbacks, we engineered cysteine variants of G-CSF to facilitate the maleimide PEG-based sitespecific PEGylation that leads to a highly homogenous PEGylated product. Importantly, we have demonstrated that $20 \mathrm{kDa}$ thiol-reactive PEG conjugated by maleimide chemistry to the Cys2 G-CSF variant exhibits leukocyte proliferative activity similar to that of the commercially available G-CSF conjugated with aldehyde PEG in a neutropenia mice model. Moreover, we have demonstrated that PEGylation of the cysteine variant of huG-CSF with higher molecular weight PEGs, such as $30 \mathrm{kDa}$ PEG and $40 \mathrm{kDa}$ $P E G$, leads to significantly prolonged leukocyte proliferation activity compared to the variant conjugated with $20 \mathrm{kDa}$ PEG. Importantly, even a half-dose of the engineered variant conjugated with $40 \mathrm{kDa}$ PEG exhibited significantly longer biological activity than the commercially available 20 kDa PEGylated huG-CSF. Finally, we have demonstrated that administration of the engineered variant conjugated with $40 \mathrm{kDa} P E G$ on the day of administration of cyclophosphamide for inducing neutropenia in mice can alleviate neutropenia through leukocyte proliferation. In summary, this study provides the design of site-specific PEGylated huG-CSF variants with improved therapeutic potential. It opens the possibility of long-acting and same-day prophylactic administration of G-CSF after chemotherapy drug regimens. These results may pave the way for the development of potential G-CSF derivatives possessing longer half-lives and favorable clinical attributes.

Keywords: G-CSF, PEGylated G-CSF, site-specific PEGylation, prolonged biological activity of G-CSF, neutropenia, cancer chemotherapy 


\section{INTRODUCTION}

Human granulocyte colony stimulating factor (huG-CSF) is a $19 \mathrm{kDa}$ cytokine that stimulates the proliferation, maturation, and functional activation of the cells in the granulocyte lineage (Anderlini et al., 1996; Welte et al., 1996). HuGCSF was approved by the Food and Drug Administration (FDA) of the United States to prevent and treat neutropenia, for bone marrow transplantation, and to mobilize peripheral blood progenitor cells for transplantation as well as for blood banking (Nemunaitis, 1997; Nervi et al., 2006). In fact, G-CSF's prophylactic administration is recognized as a critical factor behind the success of chemotherapy in cancer treatment (Crawford et al., 2004; Lyman, 2006). G-CSF is cleared from the human body through various means, including receptormediated endocytosis followed by its degradation (Kuwabara et al., 1996), renal clearance (Kuwabara et al., 1995), and enzymatic degradation mechanism (El Ouriaghli et al., 2003). Therefore, G-CSF has a short circulation half-life of about $3.5 \mathrm{~h}$ (Ng and Tang, 2013). This necessitates the administration of daily injections to maintain the effective concentration in the body to combat neutropenia.

Several approaches have been employed to increase the serum half-life of recombinant huG-CSF. These include conjugation with polyethylene glycol (PEG), known as PEGylation (Molineux, 2004), conjugation with the sialic acid (DeFrees et al., 2006), attachment with the human serum albumin (Paige et al., 1995; Halpern et al., 2002), dimerization of G-CSF (Fidler et al., 2011), a fusion of G-CSF with Fc Domain (Cox et al., 2014), circularization of G-CSF (Miyafusa et al., 2017), conjugation with transferrin (Chen et al., 2010), etc., However, PEGylation has emerged as the method of choice to increase serum half-life and reduce G-CSF's immunogenicity (Molineux, 2003). PEGylated G-CSF has significantly improved serum half-life (up to $42 \mathrm{~h}$ ) and is thus administered once-percycle of chemotherapy compared to the daily dose of G-CSF (Crawford, 2003). Given these benefits, in 2002, the FDA approved the administration of PEGylated huG-CSF as a prophylactic and therapeutic drug (Molineux, 2004). PEGylation increases the serum half-life of therapeutic proteins primarily through increasing hydrodynamic radii and thereby reducing renal clearance. Besides, PEGylation also masks the protein's surface to protect it from proteases, antibodies, and antigen processing cells, thus increasing half-life. Furthermore, PEG imparts favorable attributes on the polypeptides to improve their biological distribution and solubility (Pasut and Veronese, 2009). To increase the in vivo half-life of G-CSF, $20 \mathrm{kDa}$ methoxy PEG propionaldehyde was conjugated to the alphaamino group of the first amino acid residue of huG-CSF to make PEGylated G-CSF (Arvedson et al., 2015). Although this method results in efficient PEGylation of G-CSF and is used to PEGylate the currently available commercial G-CSF drug, there are inherent disadvantages associated with this method. This method's usage leads to a heterogeneous mixture of monoPEGylated G-CSF due to PEGylation at the epsilon amino group of lysine residues present in G-CSF in addition to PEGylation at the N-terminal amino group. G-CSF contains four lysine residues that could also be PEGylated in an aldehyde-based PEGylation strategy (Figure 1A). Notably, some of the lysine residues are located in regions implicated in binding with the G-CSF receptor (Yamasaki et al., 1994; Tamada et al., 2006). Such heterogeneous populations of drug molecules create difficulty in physicochemical characterization and, most importantly, in accurately predicting the biological activity (Pfister and Morbidelli, 2014). Furthermore, despite the administration of PEGylated G-CSF, a significant number of patients still develop neutropenia, suggesting a need for longer-lasting and more efficient versions of PEGylated G-CSF (Bartel et al., 1987; Lyman et al., 2010; Chan et al., 2011).

The second generation of site-specific PEGylation methods has been described for generating more homogenously PEGylated proteins (Pasut and Veronese, 2012; Dozier and Distefano, 2015). Over the last few years, maleimide chemistry has been utilized for the PEGylation of the thiol group of cysteine in therapeutic proteins. Given that this method has very high specificity for cysteine residues in the protein and there are only a few free cysteines in a protein, this technique has become the method of choice for PEGylation of therapeutics (Doherty et al., 2005; Rosendahl et al., 2005). This method also provides an opportunity to engineer more stable and improved variants of therapeutic proteins through addition, substitution, and deletion of cysteines. Earlier, we have published that the PEGylation of streptokinase (SK, a thrombolytic agent that dissolves fibrin blood clots) decreases antigenicity and increases in vivo half-life (Sawhney et al., 2016b). Subsequently, we showed that the PEGylation of truncated streptokinase enhanced plasmin resistance, prolonged half-life, improved fibrin clot-specificity, and reduced immunereactivity compared to the native SK (Sawhney et al., 2016a). More recently, we have also shown that the site-specific PEGylation of microplasmin, a potential therapeutic for in situ stroke intervention, significantly enhanced functional half-life via decreasing antiplasmin-mediated inhibition. The positioned PEGylated microplasmin not only prolongs renal/metabolic clearance rates but also minimizes microplasmin-antiplasmin intermolecular interactions, consequently slowing the inhibitory reaction (Kaur et al., 2019).

The site-specific PEGylation has also been employed for the PEGylation of G-CSF. G-CSF contains one free cysteine (at position 17) and two disulfide bonds (Cys36-Cys42 and Cys64-Cys74). These disulfide bonds are critical for structural integrity and G-CSF activity; however, Cys17 could be mutated. Interestingly, Cys17 was also utilized for generating a PEGylated version of G-CSF (Veronese et al., 2007). Since the cysteine 17 is partially buried in a hydrophobic pocket, this method requires denaturation followed by PEGylation and subsequent protein renaturation. Thus, this cysteine is not suitable for site-specific PEGylation. It is worth mentioning that mutation of Cys17 to alanine or serine improves its stability (Ishikawa et al., 1992), permitting the insertion/substitution of cysteine at desirable positions to impart desired traits. Conventionally, $20 \mathrm{kDa}$ PEG has been conjugated to G-CSF, but higher-molecular-weight PEG aldehydes were also conjugated. Interestingly, PEGylation with $30 \mathrm{kDa}$ aldehyde PEG instead of $20 \mathrm{kDa}$ (used in commercial 


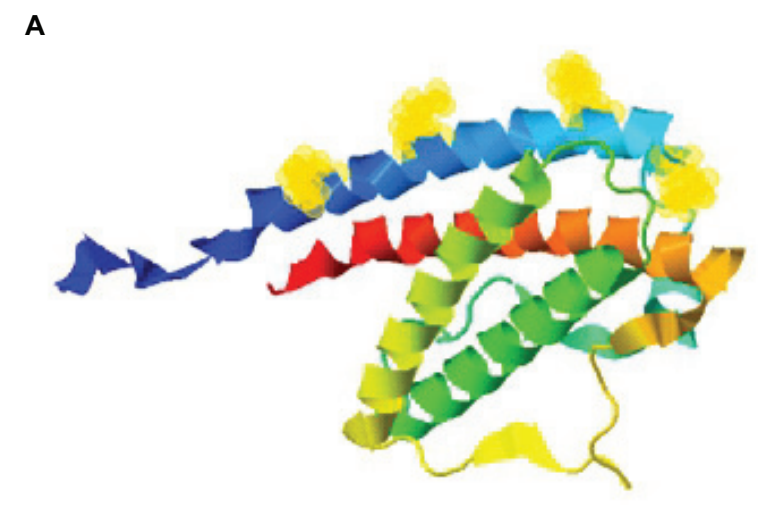

B

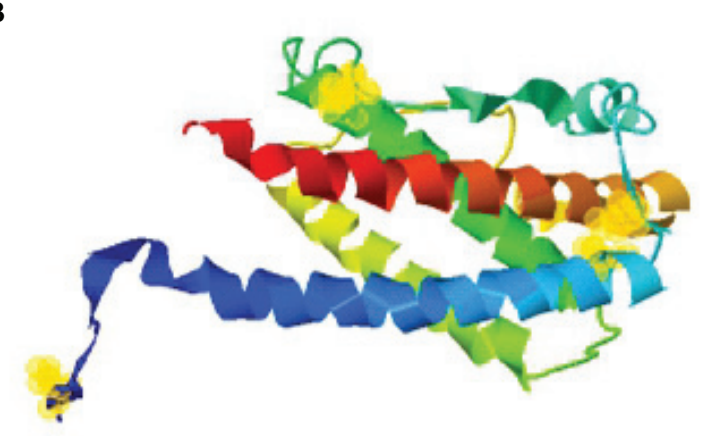

C

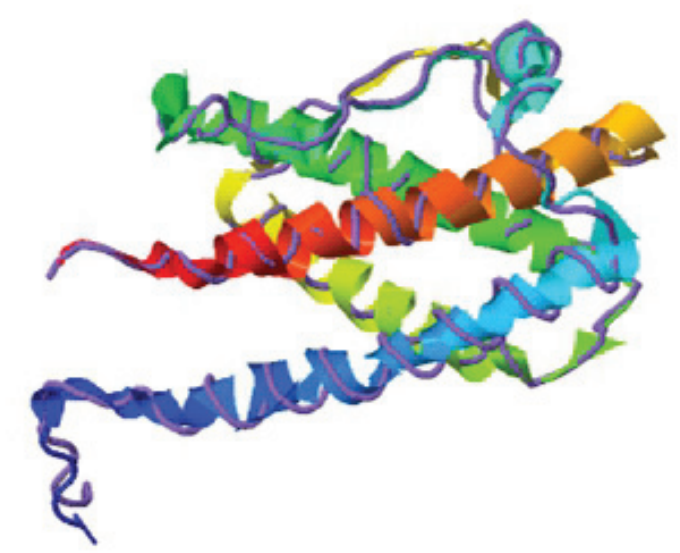

FIGURE 1 | Structure assembly simulation of G-CSF using I-TASSER webserver. (A) The position of four lysine residues (at positions 16, 23, 34, and 40) in G-CSF structure by selection halos. (B) Cysteine position in the Cys2 variant and four indigenous cysteines involved in two disulfide bonds in the Cys2 G-CSF variant by selection halos. (C) The structure assembly simulation using the I-TASSER TM-align structural alignment program to compare the structures of the Cys2 variant (shown in multicolor ribbon cartoon) and human G-CSF (displayed in purple backbone trace). Helix A, B, $\mathrm{C}$, and $\mathrm{D}$ are shown in blue, green, yellow, and red, respectively. Lysine and cysteine positions are depicted with yellow halos.

PEGylated G-CSF) at N-terminal resulted in increased serum half-life and higher bioavailability (Zhai et al., 2009).

In the present study, we utilized a computational approach for identifying strategically defined solvent-accessible sites wherein cysteines could be introduced or substituted without affecting G-CSF activity. Solvent accessibility is essential for efficient and homogenous PEGylation. G-CSF PEGylation was carried out at these sites, using methoxy PEG maleimide moiety of different molecular weights. PEGylation and homogeneity of the reaction product were confirmed using various physicochemical methods. Finally, prolonged and enhanced activity was detected in the neutropenia mice model through neutrophils' enumeration in mice blood.

\section{MATERIALS AND METHODS}

\section{Materials}

All enzymes and reagents required for molecular biology were acquired from Fermentas (Waltham, MA, United States). Purification of plasmid and DNA from agarose gel was performed using kits available from Qiagen (Hilden, Germany). Expression host Escherichia coli strain BL21 (DE3) was procured from Novagen Inc. (Madison, WI, United States). The oligonucleotide primers used in the study for cloning and site-directed mutagenesis were custom synthesized from Integrated DNA Technologies (IDT), United States, and BioServe Biotechnologies (India) Pvt Ltd., G-CSF standards $(09 / 136$ and $12 / 188)$ were purchased from the National Institute for Biological Standards and Control (NIBSC). Commercially available G-CSF and its PEGylated versions were from Dr. Reddy's Laboratories Ltd., Methoxy PEG maleimide reagents were purchased from JenKem Technology, United States. Methoxy PEG maleimide with catalog nos. A3115, A3116, and A3123 were used in this study. SPSepharose, Macro CAP SP, Capto SP ImpRes, Superdex-75 pg, and Superdex-200 pg resins and columns used for different chromatographic processes were procured from GE-Healthcare Life Science, Sweden. Zeba Spin Desalting Columns were purchased from Thermo Fisher Scientific, United States. Spectrophotometric analysis was performed on Perkin Elmer LAMBDA $35 \mathrm{UV} / \mathrm{Vis}$ spectrophotometer. All the reagents were of the highest available analytical grade. We used an AKTA Pure M (25M1) chromatographic system with Unicorn 7.3 software, version 7.3. Cyclophosphamide (C7397) was from Sigma-Aldrich. B.D. Vacutainer K3EDTA tubes were used to collect mice's blood.

\section{Construction of G-CSF Variants and Their Expression}

The human cDNA G-CSF sequence was retrieved from NCBI GenBank $^{1}$ using accession number M13008.1. This sequence was codon-optimized for expression in $E$. coli using the OptimumGene ${ }^{\mathrm{TM}}$ algorithm from GenScript, United States. The codon-optimized cDNA sequence of human G-CSF was cloned at the NdeI and HindIII sites of the expression vector pET23a using primers IMTSD1 5’ ATG ACG CCG CTG GGT CCG 3' and IMTSD2 5' CGG CTG TGC CAG GTG AC 3'. Free cysteine at position 17 of G-CSF was replaced with serine by

\footnotetext{
${ }^{1}$ https://www.ncbi.nlm.nih.gov/genbank/
} 
site-directed mutagenesis to prevent unwanted PEGylation using primers SDM17a 5' CTG CTG AAG TCT CTG GAA CAA 3' and SDM17b 5' TTG TTC CAG AGA CTT CAG CAG 3'. The cysteine substitution and or insertion variants were derived from the G-CSF variant in which cysteine 17 has been changed to serine. G-CSF variants were created using standard protocols of site-directed mutagenesis or by PCR using primers with desired changes for insertion or substitution of cysteine at a particular position in the coding sequence, as reported earlier (Kaur et al., 2019). For the Cys2 variant described in this manuscript, the following oligonucleotides were used: SDC2 5' ATG TGT CCG CTG GGT CCG 3' as forward and IMTSD2 5' CGG CTG TGC CAG GTG AC 3' as reverse primer. These cysteine variants were used to transform the BL21 (DE3) strain of E. coli for protein expression.

\section{Structure Modeling of G-CSF Variants}

The structure assembly simulation of G-CSF was performed using the I-TASSER web server (Roy et al., 2010). This was performed to simulate lysine residues and cysteine substitution or insertion position on the G-CSF structure. The TM-align structural alignment program was also run to compare G-CSF Cys2 I-TASSER simulation to all the available structures in the PDB library.

\section{Determination of Solvent-Accessible Sites}

We also utilized computational biology for identifying the regions wherein cysteines could be introduced or substituted for assisting maleimide-based PEGylation. Solvent accessibility was determined using webserver NetSurfP-2.0 (Petersen et al., 2009). This server provides the protein surface accessibility score and secondary structure predictions. The absolute surface accessibility values are a vital parameter to ascertain the solvent accessibility of the residues.

\section{Purification of G-CSF}

The G-CSF and cysteine variants cloned in the T7 RNA polymerase inducible promoter-based expression vector $\mathrm{pET} 23 \mathrm{a}$ were used to transform the BL21 (DE3) strain of E. coli. $0.5 \mathrm{mM}$ isopropyl $\beta$-D-1-thiogalactopyranoside (IPTG) was used to induce protein in the form of inclusion bodies, which were then solubilized in $2 \mathrm{M}$ urea. Washed inclusion bodies (IB) were solubilized in urea containing buffer (2 $\mathrm{M}$ urea in $50 \mathrm{mM}$ Tris- $\mathrm{HCl}, \mathrm{pH}$ 12.0) for $60 \mathrm{~min}$. After centrifugation at $11,000 \mathrm{rpm}$ for $20 \mathrm{~min}$ at $4^{\circ} \mathrm{C}$, the supernatant containing the solubilized IBs was collected. The $\mathrm{pH}$ was adjusted to 8.0 by using glacial acetic acid. Partially unfolded protein was further subjected to a two-step refolding procedure using refolding buffers $(50 \mathrm{mM}$ Tris- $\mathrm{Cl} \mathrm{pH} 8.0,50 \mathrm{mM} \mathrm{NaCl}$ and $5 \mathrm{mM}$ EDTA for $12-16 \mathrm{~h}$ followed by $25 \mathrm{mM}$ sodium acetate $\mathrm{pH}$ 4.5, $50 \mathrm{mM} \mathrm{NaCl}$, and $5 \mathrm{mM}$ EDTA $\mathrm{pH} 8.0$ for $6-8 \mathrm{~h}$ or till the $\mathrm{pH}$ of the sample reached 4.5 ) at $4^{\circ} \mathrm{C}$ with gentle stirring. Each refolding step is given 1-2 change of buffer for efficient refolding of the protein. Refolded protein was purified using cation exchange chromatography (CEC) on Capto
SP ImpRes resins from GE-Healthcare Life Science, Sweden, equilibrated with $25 \mathrm{mM}$ sodium acetate $\mathrm{pH} 4.5,50 \mathrm{mM} \mathrm{NaCl}$, and $5 \mathrm{mM}$ EDTA. The G-CSF protein was eluted using $1 \mathrm{M}$ Tris-Cl, $\mathrm{pH}$ 8.0.

\section{Conjugation of PEG to G-CSF and Purification of PEGylated G-CSF}

In the case of the cysteine variants of G-CSF, the cation exchange purified protein was used to conjugate PEG of varying sizes. The protein was dialyzed in PEGylation buffer, i.e., sodium phosphate buffer ( $\mathrm{pH}$ 7.5). The 5-fold molar excess of thiolspecific PEG was used to conjugate the Cys2 G-CSF variant in PEGylation buffer. The reaction was allowed to proceed at $20^{\circ} \mathrm{C}$ for $12-16 \mathrm{~h}$ with slow stirring. The PEGylation reaction was dialyzed against $25 \mathrm{mM}$ sodium acetate $\mathrm{pH} 4.5$ and $5 \mathrm{mM}$ EDTA. The PEGylated species were purified by CEC using MacroCap SP resins or Capto SP ImpRes resins (from GEHealthcare Life Science, Sweden), followed by size exclusion chromatography (SEC) using Superdex-75 pg or Superdex$200 \mathrm{pg}$ column. The CEC purified PEGylated protein was loaded onto the Superdex column, preequilibrated with $25 \mathrm{mM}$ sodium acetate $\mathrm{pH} 4.5,50 \mathrm{mM} \mathrm{NaCl}$ and $5 \mathrm{mM}$ EDTA and eluted in the same buffer. Fractions containing the purified protein were collected and desalted in formulation buffer [10 mM sodium acetate ( $\mathrm{pH} 4.5$ ), 5\% sorbitol and $0.004 \%$ Tween 20, followed by filtration using $0.22 \mu \mathrm{m}$ filter] and stored at $-20^{\circ} \mathrm{C}$.

\section{Analytical Characterization of PEGylated G-CSF Variants}

All PEGylated and non-PEGylated derivatives were checked for their purity on $10.5 \%$ non-reducing SDS-PAGE and stained with Coomassie Brilliant Blue (CBB). Barium iodide staining was also used to visualizing the PEGylated G-CSF. To examine the PEGylated protein, barium iodide staining was performed, where PEG moiety is stained based on the formation of a barium iodide complex with PEG. The gel was treated with $5 \%$ barium chloride solution for $10 \mathrm{~min}$ and then with $0.1 \mathrm{M}$ iodine solution for $5 \mathrm{~min}$ (Kurfurst, 1992; Zheng et al., 2007).

\section{Mass Spectrometry Analyses}

The molecular mass of G-CSF, cysteine variants, and PEG conjugated variants were determined by Matrix-Assisted Laser Desorption Ionization Time of Flight Mass Spectrometry (MALDI-TOF) on an ABI SCIEX machine, model TripleTOF ${ }^{\circledR}$ $5600 / 5600^{+}$.

\section{Circular Dichroism Spectroscopy}

Circular dichroism (CD) spectroscopy was performed to investigate the secondary structure of G-CSF, cysteine variants, and PEG-conjugated variants. Far-UV CD spectra of wild-type and modified variants were recorded from 195 to $250 \mathrm{~nm}$ on the Jasco J-815 spectro-polarimeter at $25^{\circ} \mathrm{C}$. Measurements of all the samples were performed at concentrations $0.2 \mathrm{mg} / \mathrm{ml}$, using cuvettes of $0.1 \mathrm{~cm}$ path length. 


\section{Formulation of G-CSF, Cysteine Variants, and PEG-Conjugated Cysteine Variants for Analyzing in vivo Bioactivity in a Neutropenia Mice Model}

PEGylated cysteine variants were formulated in a formulation buffer consisting of $10 \mathrm{mM}$ sodium acetate ( $\mathrm{pH} 4.5$ ), 5\% Sorbitol, and $0.004 \%$ Tween 20 , followed by filtration using a $0.22 \mu \mathrm{m}$ filter. Protein samples were aliquoted for subsequent usage and stored at $-20^{\circ} \mathrm{C}$. Before administration in mice, samples were quantitated by NanoDrop (Thermo Scientific ${ }^{\mathrm{TM}}$ ) and by running on $10.5 \%$ non-reducing SDS-PAGE gel. Quantitation was done using ImageJ software.

\section{In vivo Experiments on Neutropenia Mice}

All the mice experiments were approved by the Institutional Animal Ethics Committee of Council of Scientific and Industrial Research-Institute of Microbial Technology (IAEC Approval no. IAEC/16/05 and IAEC/18/14). These experiments were performed according to the guidelines issued by the Committee for the Purpose of Supervision of Experiments on Animals (No.55/1999/CPCSEA) under the Prevention of Cruelty to Animals Act 1960 and amendments introduced in 1982 by the Ministry of Environment and Forest, Govt. of India. Mice were maintained and bred in the animal house facility of CSIR-Institute of Microbial Technology; 8-12-week-old male $\mathrm{BALB} / \mathrm{c}$ mice were used in the current study for analyzing the biological activity of PEG-conjugated cysteine variants of G-CSF. Toward this, mice were acclimatized for a week, and neutropenia was induced in mice using an intraperitoneal injection of cyclophosphamide ( $200 \mathrm{mg} / \mathrm{kg}$ body weight of mice) as per standard procedures. Cyclophosphamide is an anti-cancer chemotherapy drug. This medication is classified as an alkylating agent and also used to induce neutropenia in laboratory animals (Scholz et al., 2009). To confirm neutropenia induction, blood was withdrawn and collected in K3EDTA Vacutainer tubes, and total leukocyte counts (TLC) were measured. TLC was determined using the HmX Hematology Analyzer from Beckman Coulter, and data were also confirmed by Leishman's staining. One-day post-induction of neutropenia, sham (having formulation buffer without therapeutic protein), PEGylated G-CSF (commercially available), and the engineered cysteine PEGylated variants were independently administered as the single subcutaneous dose. To analyze the effect of increasing the molecular weight of PEG on neutrophil proliferation, $40 \mu \mathrm{g}$ of each protein was administered as a single subcutaneous dose. The equimolar concentration of standard G-CSF and Cys2 $40 \mathrm{kDa}$ PEGylated G-CSF was administered to analyze the effect of the Cys2 variant on the day of cyclophosphamide treatment. To investigate the effect of the half-dose of Cys2 $40 \mathrm{kDa}$ PEGylated variant on neutrophil proliferation, mice were administered $1 \mathrm{mg} / \mathrm{kg}$ of mice weight of standard G-CSF or $0.5 \mathrm{mg} / \mathrm{kg}$ of mice weight of Cys $240 \mathrm{kDa}$ PEGylated G-CSF. After G-CSF treatment, the blood samples were withdrawn from the retro-orbital plexus, and TLC counts were determined every third day $\left(3^{\text {rd }}, 6^{\text {th }}, 9^{\text {th }}, 12^{\text {th }}\right.$, and $15^{\text {th }}$ day).

\section{Statistical Analysis}

GraphPad Prism 6 for Windows, Version 6.05, was used to plot animal experiment data. The plots represent scatter dot plot wherein data are means with SEM for three mice per group. Statistical significance was determined using two-way ANOVA multiple comparisons of the data. ${ }^{*}$ indicates a $P$-value $<0.05$, **indicates a $P$-value $<0.01,{ }^{* * *}$ indicates a $P$-value $<0.001$, and $* * * *$ indicates a $P$-value $<0.0001$.

\section{RESULTS}

\section{Identification and Selection of Optimal Sites for Inserting and or Substituting Cysteine}

With the overarching goal of creating PEGylated variants with prolonged biological activity, we utilized computational biology for identifying the regions wherein cysteines could be introduced or substituted for assisting maleimide based PEGylation. Toward this, we analyzed the structure of G-CSF for the identification of solvent-accessible sites, wherein PEGylation will not impede the activity and binding with G-CSF receptor. Available structure of G-CSF complexed with the ligand-binding region of the G-CSF receptor was used for this purpose (Aritomi et al., 1999; Tamada et al., 2006). It is important to note that all the cysteine substitution variants were derived from the G-CSF variant in which cysteine 17 has been changed to serine. This was done to ensure mono-PEGylation on single free thiol group of engineered cysteine in G-CSF. We reasoned that solvent accessibility would increase the efficiency of the PEG conjugation of G-CSF, besides shielding the protein from proteases and thereby increasing the in vivo half-life. Solvent accessibility was determined using webserver NetSurfP-2.0 (Petersen et al., 2009). This server provides the values for absolute surface accessibility. Detailed analysis with this server for G-CSF revealed that $\mathrm{N}$ - and $\mathrm{C}$-terminal regions have unstructured solvent-accessible regions. Besides, we also observed that loop region between helix $\mathrm{C}$ and $\mathrm{D}$ is also unstructured and is solvent-accessible. Based on these considerations, several solvent-accessible sites that would not impede G-CSF's biological activity were identified (listed in Table 1). We choose substitution of threonine with cysteine after the first amino acid methionine to provide a proof of concept. This variant (referred as Cys2 variant hereafter) was utilized for the rest of the studies presented in this manuscript. We also performed a structure assembly simulation of G-CSF using the I-TASSER web server (Roy et al., 2010; Figures 1A,B). Furthermore, we utilized the TM-align structural alignment program to compare G-CSF Cys2 I-TASSER simulation to all the structures in the PDB library, which confirmed the substitution of cysteine at position 2 does not affect the salient structural features of the G-CSF (Figure 1C).

\section{Cloning, Expression, and Purification of the Cys2 Variant}

The codon-optimized cDNA sequence of human G-CSF was cloned in the expression vector pET23a. Free cysteine at 
TABLE 1 | The preferred position for cysteine substitution or insertion for site-specific PEGylation of G-CSF\# .

\begin{tabular}{ll}
\hline Proximal to Helix A Amino acid 1-10 & $\mathrm{T} 1, \mathrm{P} 2, \mathrm{~L} 3, \mathrm{G} 4, \mathrm{P} 5, \mathrm{A6}, \mathrm{S7}, \mathrm{S} 8 \mathrm{MCT}_{1}, \mathrm{~T}_{1} \mathrm{CP}_{2}, \mathrm{P}_{2} \mathrm{CL}_{3}, \mathrm{~L}_{3} \mathrm{CG}_{4}, \mathrm{G}_{4} \mathrm{CP}_{5}, \mathrm{P}_{5} \mathrm{CA}_{6}, \mathrm{~A}_{6} \mathrm{CS}_{7}$ \\
Helix A Amino acid 11-39 & $\mathrm{E} 33, \mathrm{~K} 34$ \\
AB loop Amino acid 40-70 & $\mathrm{K} 40, \mathrm{~L} 61$ \\
Helix B Amino acid 71-91 & $\mathrm{Q} 90$ \\
BC loop Amino acid 92-99 & $\mathrm{P} 97, \mathrm{E} 98, \mathrm{~L} 99, \mathrm{~S}_{96} \mathrm{CP}_{97}, \mathrm{P}_{97} \mathrm{CE}_{98}, \mathrm{~L}_{99} \mathrm{CG}_{100}$ \\
Helix C Amino acid 100-123 & $\mathrm{P} 101, \mathrm{E} 122, \mathrm{E} 123, \mathrm{P}_{101} \mathrm{CT}_{102}, \mathrm{M}_{121} \mathrm{CE}_{122}, \mathrm{E}_{122} \mathrm{CE}_{123}$ \\
CD Loop Amino acid 124-142 & $\mathrm{P} 128, \mathrm{P} 138, \mathrm{~L}_{124} \mathrm{CG} \mathrm{G}_{125}, \mathrm{M}_{126} \mathrm{CA}_{127}, \mathrm{Q}_{134} \mathrm{CG}_{135}, \mathrm{P}_{138} \mathrm{CA}_{139}$ \\
Helix D Amino acid 143-172 & $\mathrm{R} 146, \mathrm{R} 147, \mathrm{R} 169, \mathrm{H} 170, \mathrm{~L}_{171}, \mathrm{~A}_{172}, \mathrm{~A}_{143} \mathrm{CF}_{144}, \mathrm{R}_{146} \mathrm{CR}_{147}, \mathrm{R}_{169} \mathrm{CH}_{170}, \mathrm{H}_{170} \mathrm{CL}_{171}, \mathrm{~L}_{171} \mathrm{CA}_{172}, \mathrm{~A}_{172} \mathrm{CQ}_{173}$ \\
Distal to Helix D Amino-acid 173-174 & $\mathrm{Q} 173, \mathrm{P} 174, \mathrm{Q}_{173} \mathrm{P}_{174} \mathrm{C}, \mathrm{Q}_{173} \mathrm{CP}_{174}$
\end{tabular}

\#Solvent accessibility was determined using webserver NetSurfP-protein surface accessibility and secondary structure prediction. This server provides the values for absolute surface accessibility, which was utilized to select solvent-accessible suitable sites for PEGylation.

position 17 was mutated to serine using site-directed mutagenesis to prevent unwanted PEGylation at Cys17. Threonine was substituted with cysteine at the N-terminal after the first methionine using standard methods. Both, the substitution of cysteine at position 2 (Cys2) and the mutagenesis of cysteine 17 to serine were confirmed using DNA sequencing. Cys2 variant was overexpressed in E. coli. Similar to the wild-type huG-CSF, this variant also resides in the inclusion bodies and was purified using denaturation with urea followed by twostep refolding and chromatographic purification (Figure 2A). SDS-PAGE analysis revealed that the purified Cys2 variant exhibits a single protein band at the right size (Figure 2B). Finally, CD spectroscopy was utilized to analyze the secondary structure of the Cys 2 variant. This analysis suggested that cysteine substitution does not affect the overall secondary structure of the Cys2 variant (Figure 2C).

\section{Mono-PEGylation, Purification, and Characterization of Cys2 Variant}

Purified Cys2 variant was conjugated with $20 \mathrm{kDa}$ methoxy PEG maleimide using maleimide chemistry. The PEGylated species were purified by CEC using MacroCap SP resins or Capto SP ImpRes resins (from GE-Healthcare Life Science, Sweden), followed by SEC (Figures 3A-B). SDS-PAGE analysis followed by $\mathrm{CBB}$ staining confirmed PEGylation of the Cys2 variant (Figure 3C). These results also suggest high efficiency of PEGylation since the non-PEGylated species were present only in minute traces. We also utilized barium iodide staining to confirm the PEGylation. Barium iodide specifically stains PEG molecules with very high sensitivity and thus could resolve PEGylated species that are not visible with the $\mathrm{CBB}$ staining. Here again, we observed highly specific mono-PEGylation of the Cys2 variant with traces of multi-PEGylated species (Figure 3D). SEC revealed highly homogenous PEGylation of the Cys2 variant (Figures 3C-D). This is important since aldehyde based amino-terminal PEGylation produces a heterogeneous mixture of multispecies of PEGylated huG-CSF (Shekhawat et al., 2019). MALDI-TOF analysis also suggested the formation of highly homogenous mono-PEGylated Cys2 variant (Figure 3E). Next, we analyzed whether PEGylation of Cys2 variant has any effect on the secondary structure of the protein. Toward this, CD spectroscopy was utilized. We observed that the secondary structure of the Cys2 variant conjugated with $20 \mathrm{kDa}$ methoxy PEG maleimide was similar to the commercially available PEGylated G-CSF drug (Figure 3F). In summary, these findings suggest that Cys2 variant of huG-CSF could be homogenously mono-PEGylated with high efficiency and exhibit similar physicochemical characterization to G-CSF drug.

\section{In vivo Biological Activity of PEGylated Cys2 Variant}

The above experiments suggested homogeneous monoPEGylation of the Cys2 variant of huG-CSF. Next we analyzed whether the PEGylated variant is biologically active or not. Toward this, we established a mice model of neutropenia. Cyclophosphamide was administered intraperitoneally in 8-12-week-old mice for inducing neutropenia. Neutropenia was confirmed through the measurement of total leukocyte counts (TLC) on day 0 . After the induction and confirmation of neutropenia, sham (having buffer only), commercially available PEGylated huG-CSF, and the mono-PEGylated Cys2 variant were independently administered as the single subcutaneous dose (summarized in the schematic provided in Figure $\mathbf{4 A}$ ). After G-CSF treatment, the blood samples were withdrawn, and TLC counts were determined on $3^{\text {rd }}$, $6^{\text {th }}$, $9^{\text {th }}$, and $12^{\text {th }}$ day. We observed that the PEGylated Cys2 variant conjugated with $20 \mathrm{kDa}$ PEG possesses similar biological activity to that of the commercially available PEGylated huG-CSF (Figure 4B). These observations suggest that Cys2 substitution in G-CSF and its PEGylation via maleimide chemistry do not hamper the activity of huG-CSF.

\section{Higher-Molecular-Weight PEGylation Leads to the Prolonged Activity of Cys2 Variant in Neutropenic Mice}

After establishing that the PEGylation of the Cys2 variant does not hamper its activity, we analyzed whether conjugation of the Cys2 variant with higher-molecular-weight PEG improves and prolongs its biological activity. The Cys2 variant was conjugated with $30 \mathrm{kDa}$ and $40 \mathrm{kDa}$ methoxy PEG maleimide. The PEGylated Cys2 variant was purified as described earlier 
A

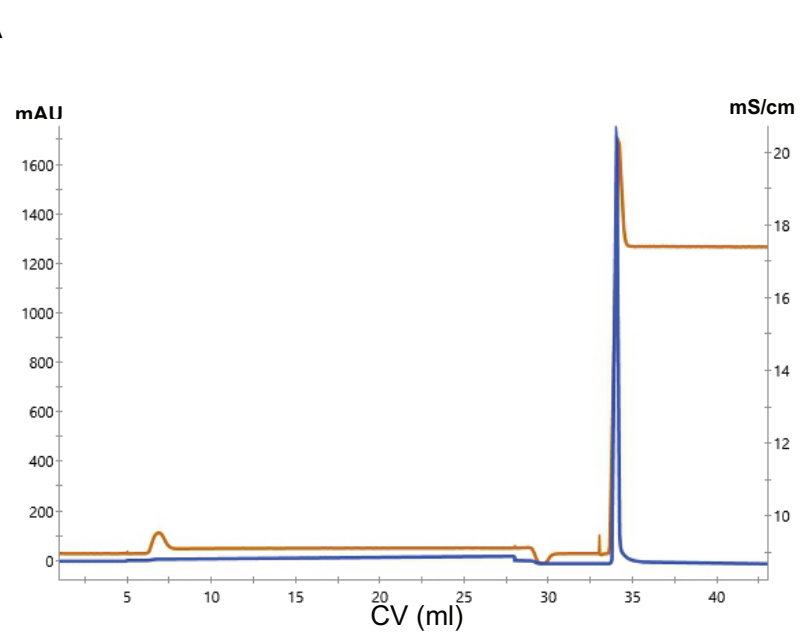

C
B

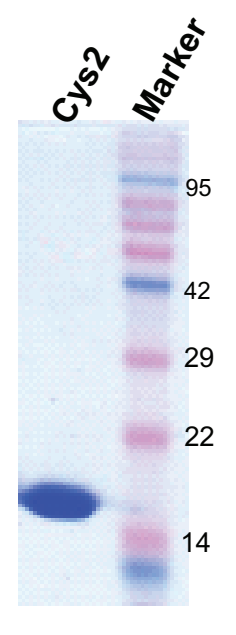

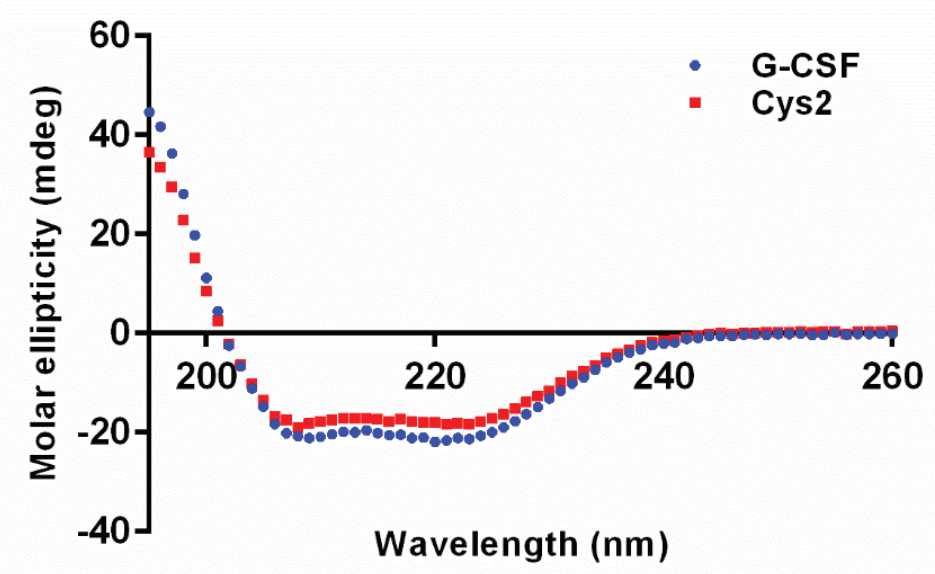

FIGURE 2 | Purification and characterization of the G-CSF Cys2 variant. (A) Cation exchange chromatography profile of the Cys2 variant of G-CSF. Protein was eluted by $1 \mathrm{M}$ Tris- $\mathrm{HCl}$. Parameters such as absorbance at $280 \mathrm{~nm}$ and conductance have been represented with blue and brown lines, respectively. (B) The SDS-PAGE profile shows the general purity of the eluted Cys2 variant protein. (C) A comparison of far UV circular dichroic spectra of Cys2 cysteine variant and wild type G-CSF.

and analyzed on non-reducing SDS-PAGE using CBB staining (Figure 5A), barium iodide staining (Figure 5B), and MALDITOF mass spectrometry (Figures 5C-D). CD spectroscopy confirmed that PEGylation with $30 \mathrm{kDa}$ and $40 \mathrm{kDa}$ PEG does not alter the secondary structure of G-CSF (Figure 5E). Finally, we analyzed the biological activity of the Cys 2 variant conjugated with $30 \mathrm{kDa}$ and $40 \mathrm{kDa}$ PEG. We observed that on sixth day post-administration, the TLC count was higher in the group that received the Cys2 variant conjugated with $30 \mathrm{kDa}$ PEG. Importantly, we also observed that TLC counts in the groups receiving Cys2-30 kDa and Cys2-40 kDa conjugates were higher on the $9^{\text {th }}$ day as compared to sham, standard, or mice receiving the Cys2-20 kDa. Furthermore, the Cys 2 variant conjugated with $40 \mathrm{kDa}$ PEG even showed higher leukocyte recovery on the $12^{\text {th }}$ day, indicating prolonged biological activity (Figure 4B). These data clearly show that the G-CSF variant conjugated with higher-molecular-weight
PEG possesses prolonged biological activity, perhaps due to longer in vivo retention of the Cys2-30 $\mathrm{kDa}$ and Cys2$40 \mathrm{kDa}$ conjugates.

\section{Half-Dose of Cys2-40 kDa PEG Conjugate Has Improved and Longer Biological Activity Than the Full Dose of 20 kDa PEG Conjugate}

The above-described experiments suggest that the Cys2-40 kDa PEG conjugate possesses improved and longer biological activity than the Cys2-20 kDa PEG conjugate. Thus, we analyzed whether the half-dose $(0.5 \mathrm{mg} / \mathrm{kg}$ mice body weight) of the Cys $2-40 \mathrm{kDa}$ PEG conjugate could compare for biological activity with the full dose (1 mg/kg mice body weight) of the standard $20 \mathrm{kDa}$ PEG conjugate. Toward this, neutropenia was induced in mice as described above, and mice were treated with sham, a full 
A

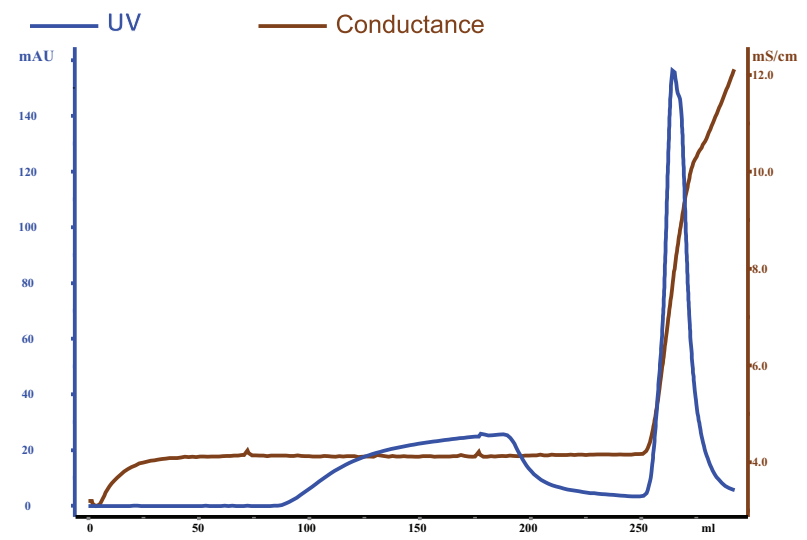

C

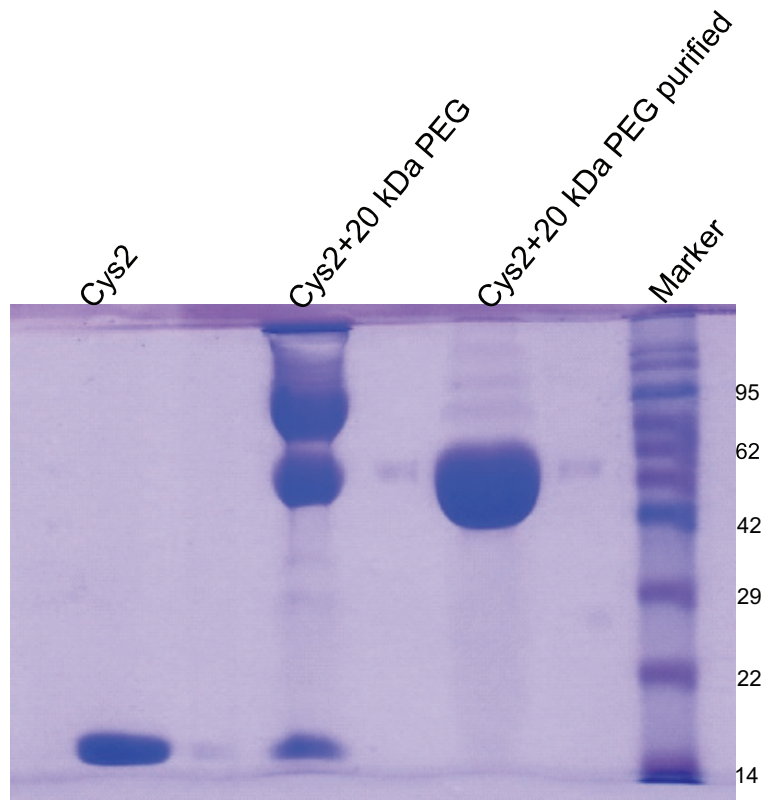

E

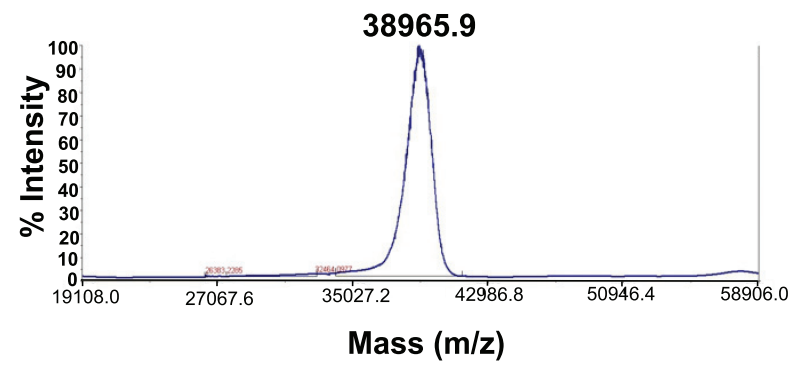

B

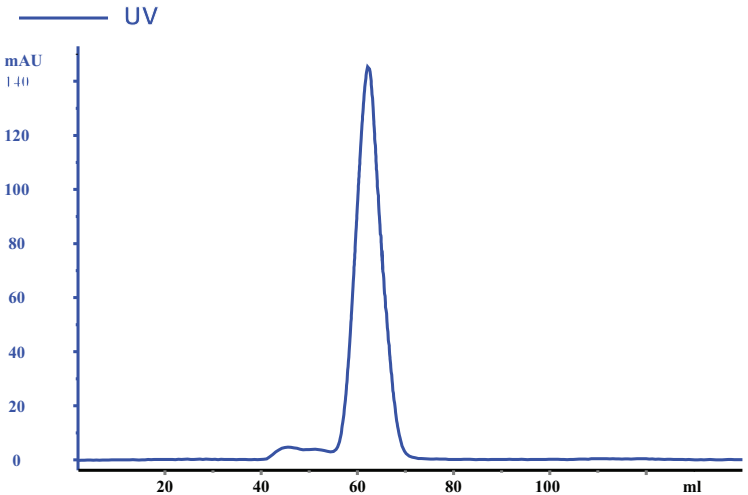

D

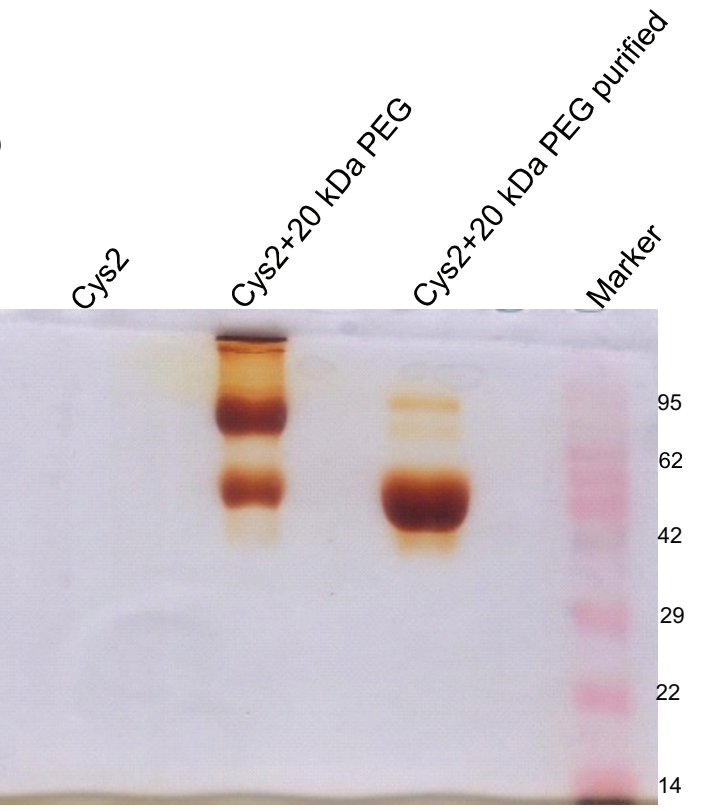

$\mathbf{F}$

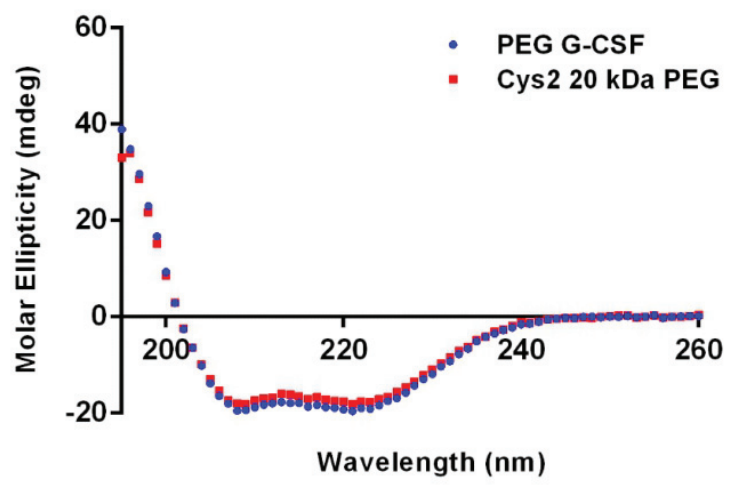

FIGURE 3 | Purification and characterization of PEGylated Cys2 variant of G-CSF. (A) The first purification step (i.e., cation exchange chromatography, CEC) profile of the $20 \mathrm{kDa}$ PEGylated Cys2 variant of G-CSF. (B) The second purification step (i.e., size exclusion chromatography, SEC) profile of CEC purified Cys2 variant protein in its PEGylated form. (C) Non-reducing SDS-PAGE profile stained with CBB showing the purity of purified PEGylated protein, wherein Lane 1 is the non-PEGylated cysteine variant, Lane 2 is the CEC-eluted peak fraction corresponding to PEG-conjugated Cys2 protein, Lane 3 is the SEC purified fraction, and Lane 4 is the Marker. (D) Same samples run on different gel and stained with barium iodide for staining specifically PEGylated protein. (E) The MALDI-TOF profile of purified Cys2 variant conjugated with $20 \mathrm{kDa}$ PEG. (F) Comparison of far UV circular dichroic spectra of Cys2 variant conjugated with $20 \mathrm{kDa}$ PEG and commercial available $20 \mathrm{kDa}$ PEGylated G-CSF. 


\section{A}

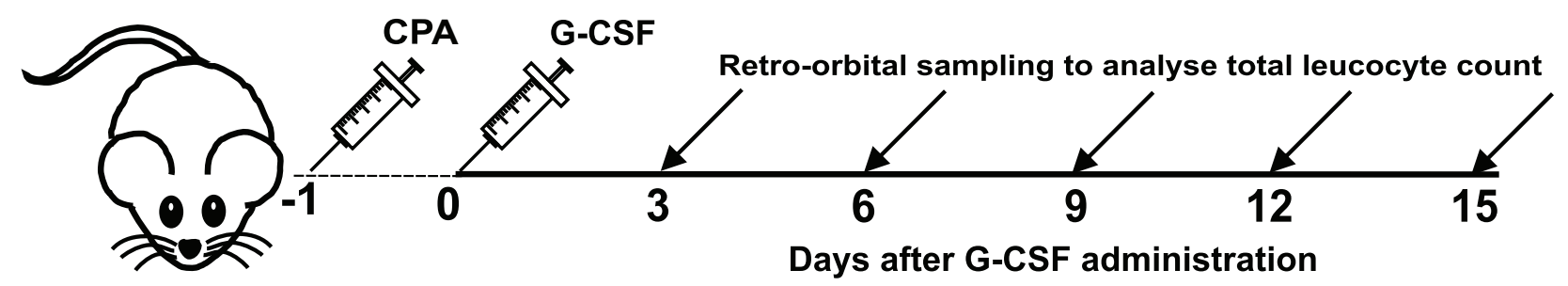

B

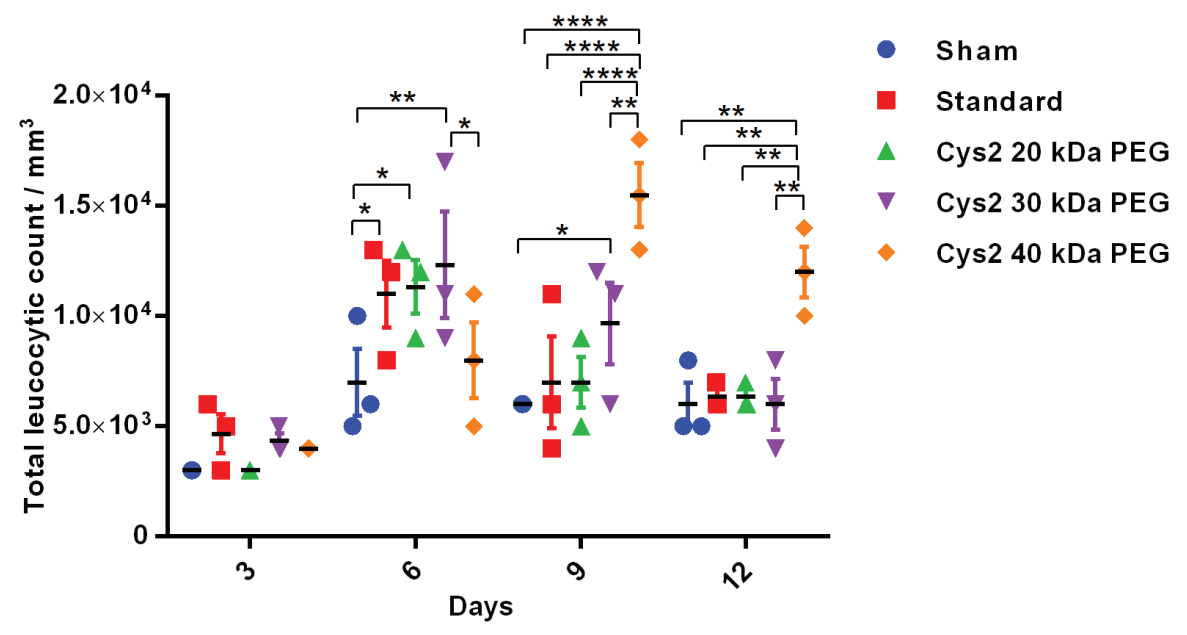

FIGURE 4 | Biological activity of PEGylated variants in a neutropenia mice model. (A) Schematic depiction of the experimental procedure. CPA denotes cyclophosphamide. (B) Biological activity comparison of commercially available $20 \mathrm{kDa}$ PEGylated G-CSF (standard) and Cys2 variant conjugated with $20 \mathrm{kDa}$, $30 \mathrm{kDa}$, and $40 \mathrm{kDa}$ methoxy PEG maleimide in neutropenic mice. Total leucocytic counts (TLC) were determined following a single subcutaneous injection of $40 \mu \mathrm{g}$ of G-CSF variants. The plots represent a scatter dot plot wherein data are means with SEM for three mice per group. Statistical significance was determined using two-way ANOVA multiple comparisons of the data. *indicates a $P$-value $<0.05$, **indicates a $P$-value $<0.01$ and ${ }^{* * \star *}$ indicates a $P$-value $<0.0001$.

dose of standard PEGylated G-CSF conjugated with $20 \mathrm{kDa}$ PEG $(1 \mathrm{mg} / \mathrm{kg}$ mice body weight) and half-dose $(0.5 \mathrm{mg} / \mathrm{kg}$ mice body weight) of the Cys2-40 kDa PEG conjugate. Importantly, we observed that on day 6 , the mice receiving a half-dose of the Cys $2-40 \mathrm{kDa}$ PEG conjugate and a full dose of $20 \mathrm{kDa}$ PEGylated G-CSF have a comparable TLC. Importantly, on day 9 and 12, the proliferation of leukocytes was significantly higher in the group receiving the half-dose of the Cys $2-40 \mathrm{kDa}$ PEG conjugate compared to the group receiving the full dose of the standard PEGylated G-CSF conjugated with $20 \mathrm{kDa}$ PEG (Figure 6A). These data suggest that even the half-dose of Cys2-40 kDa PEG conjugate has better and prolonged biological activity than the full dose of the standard PEGylated G-CSF.

\section{Same-day Administration of the Cys2-40 kDa PEG Conjugate Is Equally Effective as a Standard Regimen}

One of the challenges in prophylactic administration of G-CSF during chemotherapy is that it must be administered $24 \mathrm{~h}$ after dispensing chemotherapeutic drugs to achieve adequate prophylactic protection from neutropenia. A same-day G-CSF substitute will be beneficial and as well as convenient for patients. As the administration of Cys2 variant conjugated with $40 \mathrm{kDa}$ PEG has resulted in much longer biological activity, we checked whether the administration of the Cys2 $40 \mathrm{kDa}$ PEG conjugated variant at the day of neutropenia induction (mimicking the G-CSF treatment at the day of chemotherapy) could facilitate the recovery of leukocyte count in a neutropenic mice model. Interestingly, the same-day administration of the Cys2 variant conjugated with $40 \mathrm{kDa}$ PEG has improved leucocytic recovery at day 6, 9, and 12 as compared to the standard PEGylated G-CSF conjugated with $20 \mathrm{kDa}$ PEG administrated $24 \mathrm{~h}$ after cyclophosphamide treatment (Figure 6B).

\section{DISCUSSION}

huG-CSF is a beneficial and widely used therapeutic protein for several clinical conditions, including neutropenia, leukopenia, AIDS, sepsis, and also in patients undergoing bone marrow 
A<smiles>O=C=O</smiles><smiles>O=[14CH][O-]</smiles><smiles>C=CCCCCC</smiles>

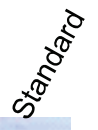
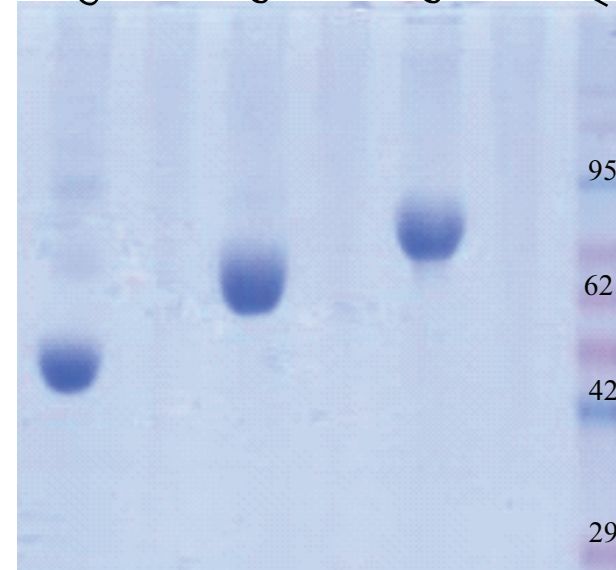

C

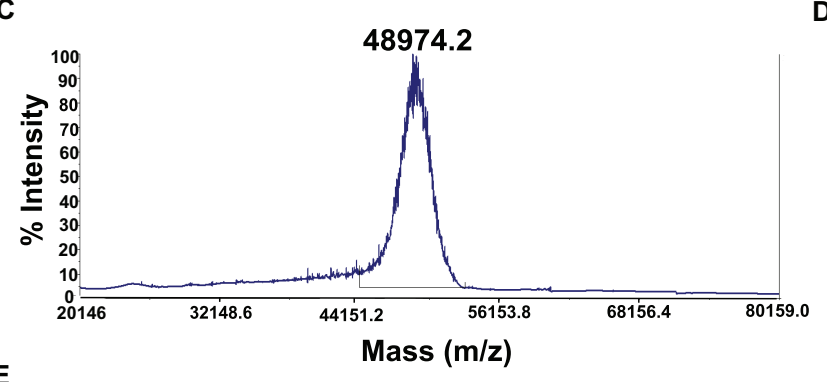

E

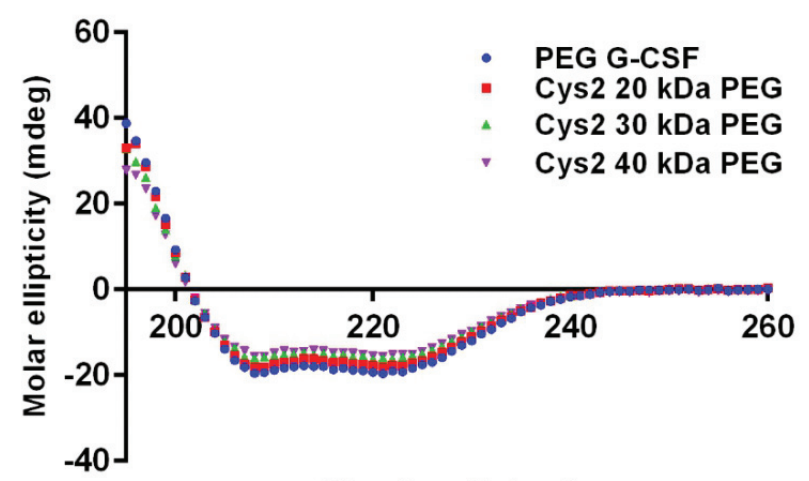

B

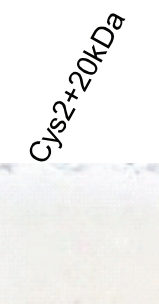<smiles>O=C=O</smiles><smiles>O=C=O</smiles><smiles>C[14CH2][14CH2]</smiles><smiles>[Co][Co]</smiles>

95

62

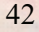

29

D

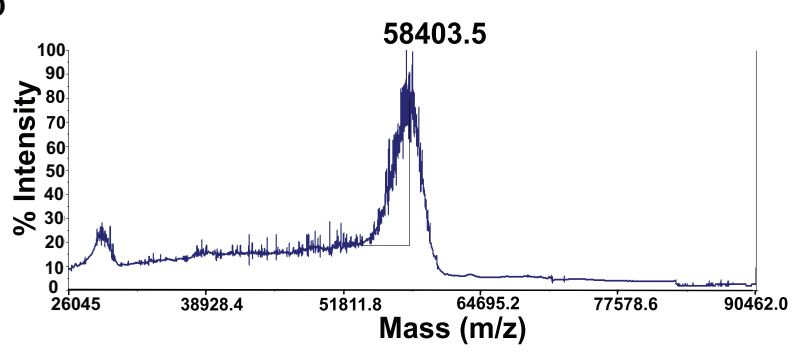

Wavelength $(\mathrm{nm})$

FIGURE 5 | Characterization of PEGylated G-CSF Cys2 variant. (A) CBB-stained non-reducing SDS-PAGE analysis of purified higher-molecular-weight PEG-conjugated Cys2 variants. (B) Barium iodide-stained gel for purified protein samples to stain specifically PEGylated protein. (C) The MALDI-TOF profile of purified Cys2 variant conjugated to $30 \mathrm{kDa}$ PEG and (D) $40 \mathrm{kDa}$ PEG. (E) Comparison of far UV circular dichroic spectra of Cys2 variant conjugated with different sizes of PEG and commercially available $20 \mathrm{kDa}$ PEGylated G-CSF.

transplantation (Mehta et al., 2015). To increase its halflife, $20 \mathrm{kDa}$ PEG aldehyde is conjugated to the first amino acid's amino group. However, this method is associated with undesired non-specific PEGylation at the epsilon amino group of lysine residues besides the alpha-amino group (Veronese, 2001). Methoxy PEG maleimide has been utilized for site-specific PEGylation at the thiol group of cysteine residue. In the present study, we have employed a computational biology approach for the identification of solvent-accessible sites for the substitution or addition of cysteine residues in the protein for facilitating maleimide based site-specific PEGylation. Based on this analysis, we chose to substitute a cysteine residue at position 2 to generate the Cys2 variant. This variant was purified and conjugated with $20 \mathrm{kDa}, 30 \mathrm{kDa}$, and $40 \mathrm{kDa}$ PEG moieties. Using various physicochemical methods, we demonstrated that PEGylation at this solvent-accessible site does not measurably alter the structure 


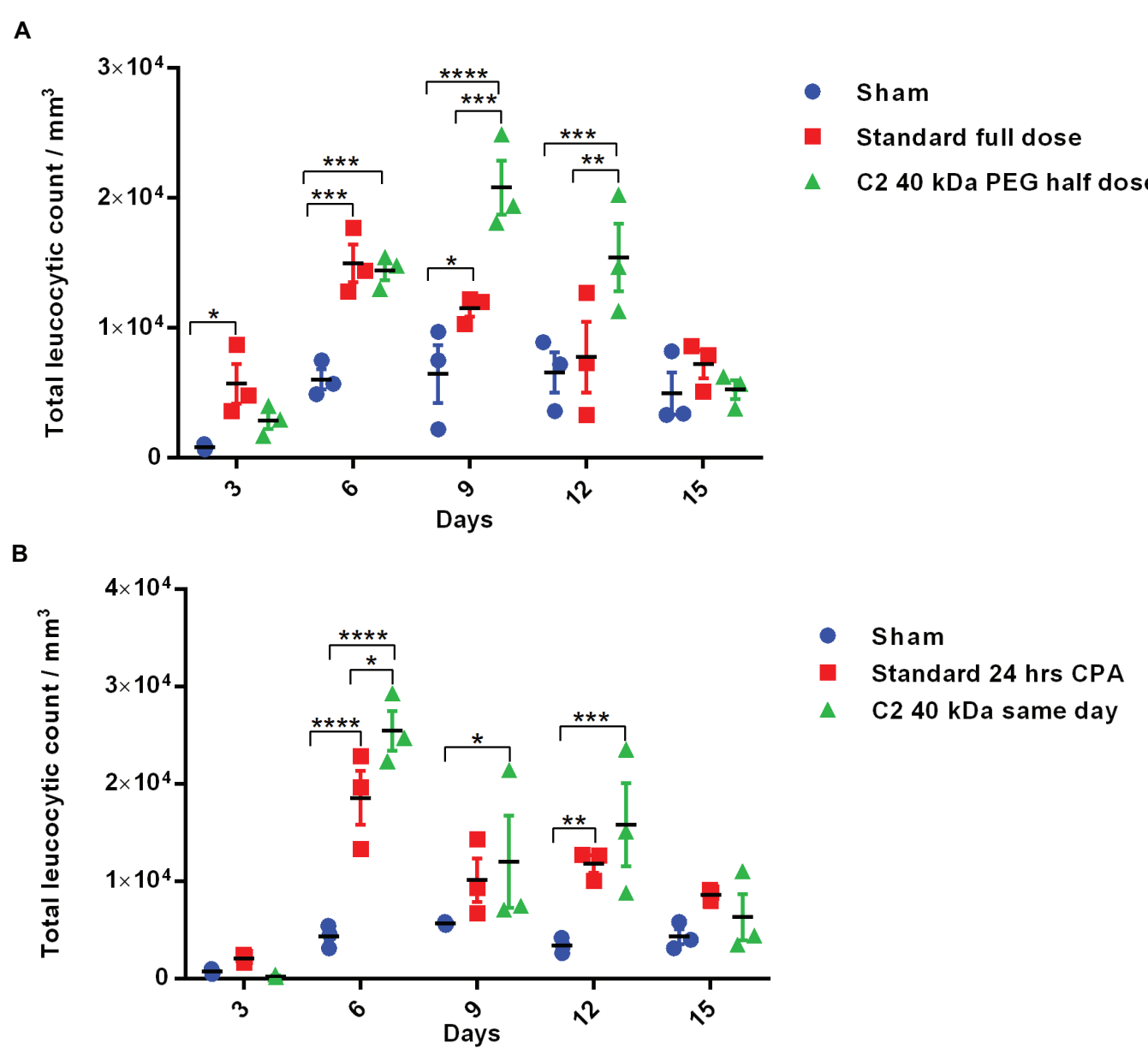

FIGURE 6 | Biological activity of half-dose and same-day administration of PEGylated variants. (A) Biological activity profile of half-dose of Cys2 variant conjugated with $40 \mathrm{kDa}$ methoxy PEG maleimide in neutropenic mice. (B) Biological activity profile of Cys2 variant conjugated with $40 \mathrm{kDa}$ methoxy PEG maleimide administered same-day (after $8 \mathrm{~h}$ of CPA treatment) and compared with the standard administered, i.e., after $24 \mathrm{~h}$ of induction of neutropenia in mice. The plots represent a scatter dot plot wherein data are means with SEM for three mice per group. Statistical significance was determined using two-way ANOVA multiple comparisons of the data. ${ }^{*}$ indicates a $P$-value $<0.05$, ${ }^{* *}$ indicates a $P$-value $<0.01,{ }^{* \star *}$ indicates a $P$-value $<0.001$ and ${ }^{* \star * * i n d i c a t e s ~ a ~} P$-value $<0.0001$.

of G-CSF. Furthermore, using the neutropenia mice model, we have shown that the $20 \mathrm{kDa}$ methoxy PEG maleimide-conjugated Cys 2 variant has similar leukocyte proliferative activity as that of the commercially available product. Importantly, we also demonstrate that conjugation of the Cys2 variant with $30 \mathrm{kDa}$ and $40 \mathrm{kDa}$ PEG prolongs its biological activity. Thus, through this site-specific, cysteine-dependent route, we can prepare engineered variants of G-CSF that are homogeneously PEGylated and exhibit clinically desirable traits that are a feature of nextgeneration G-CSF drug.

Accordingly, one of the significant findings of this study is the prolonged activity of the Cys2 variant of huG-CSF conjugated with $30 \mathrm{kDa}$ and $40 \mathrm{kDa}$ PEG compared to the $20 \mathrm{kDa}$ PEG conjugated Cys 2 variant. These are clinically relevant findings and agree with earlier studies wherein prolonged biological activity was correlated with the molecular weight of conjugated PEG moiety (Doherty et al., 2005; Sawhney et al., 2016b). Previous studies have shown that the addition of higher-molecular-weight N-terminal PEG to huG-CSF leads to decrease in its in vitro activity as monitored through the use of M-NFS-60 cell line-based assays and increase in in vivo circulation half-life (Zhai et al., 2009). It is important to note that in most of these studies, PEG molecules were in the range of 5$30 \mathrm{kDa}$, whereas in our study, we utilized PEG molecules from $20 \mathrm{kDa}$ to $40 \mathrm{kDa}$. Similar results were observed in studies toward the design and development of PEGylated G-CSF (Arvedson et al., 2015). These results have led to the hypothesis that increasing PEG's molecular weight hinders the binding of the huG-CSF with its receptor and, thus, is not ideal for in vivo use. Based on these considerations, commercial PEGylated huGCSF is conjugated to $20 \mathrm{kDa}$ PEG. Intriguingly, we observed that the conjugation of huG-CSF with $40 \mathrm{kDa}$ results in prolonged in vivo activity. In fact, even the half-dose of the $40 \mathrm{kDa} P E G$ molecule increased the proliferation of leukocytes till the $9^{\text {th }}$ day. In comparison, the commercially available $20 \mathrm{kDa}$ PEG conjugated huG-CSF was virtually exhausted after the $6^{\text {th }}$ day of 
administration. In the light of the data presented in this study, the view that high molecular PEG hinders with in vivo binding of huG-CSF with its receptor needs to be revisited.

Another significant finding of the present study was that the same-day administration of the Cys2 variant conjugated with $40 \mathrm{kDa}$ PEG effectively increased the leukocyte counts to desirable levels or more at the $6^{\text {th }}, 9^{\text {th }}$, and 12 th day. These findings are fascinating since such a method could pave the way for same-day administration of the prophylactic G-CSF variant. Currently, PEGylated G-CSF is administered $24 \mathrm{~h}$ after the administration of chemotherapeutic drugs. Thus, the patient needs to come back to the clinic for the administration of G-CSF (or its PEGylated form) 1 day after the administration of chemotherapy. We believe that innovations leading to sameday administration of chemotherapeutic and prophylactic agents could tremendously improve the outcome and be convenient for patients. We would also like to emphasize that we observed that in mice receiving same-day administration of huG-CSF$40 \mathrm{kDa}$ PEG, the proliferation of leukocytes in neutropenic mice was considerably lower at the third day when compared to the administration of $20 \mathrm{kDa}$ PEGylated G-CSF.

The production process for the currently available PEG conjugated huG-CSF relies upon amine-reactive PEGs (Molineux, 2004). Such PEGs react with the amine groups in a protein, including one at the $\mathrm{N}$-terminal. Due to the underlying biochemistry, aldehyde PEG could also PEGylate the epsilon amino group of four lysine residues of huG-CSF. Some of these lysine residues are located in regions critical for binding with the G-CSF receptor (Yamasaki et al., 1994; Tamada et al., 2006). Additionally, non-specific PEGylation at lysine residues also hinders G-CSF interaction with its receptor leading to reduced activity. Thus, this approach is not ideal for G-CSF's PEGylation, and other more specific PEGylation methods are required. In this direction, Cox and coworkers have utilized cysteine-reactive maleimide PEGs and developed methodology for site-specific PEGylation of G-CSF and other cytokines (Rosendahl et al., 2005). This method provides a unique opportunity to introduce cysteine at strategically defined sites. Building upon this methodology, we identified solvent-accessible PEGylation sites that could facilitate optimal PEGylation of G-CSF through thiol-reactive maleimide PEGs. We ensured that residues critical for G-CSF interaction with its receptor were deselected and suitable solvent-accessible sites that could be used for the PEGylation of G-CSF were identified. In all these constructs, cysteine 17 was mutated to serine to avoid non-specific PEGylation. These sites include an unstructured region at $\mathrm{N}$-terminal, $\mathrm{C}$-terminal, and the central loop regions. We utilized the $\mathrm{N}$-terminal unstructured region and substituted cysteine at position 2. Next, we demonstrated that this site could be utilized for efficient and homogenous PEGylation. Several studies have suggested that the amine-reactive PEGs lead to heterogeneous PEGylation (Pasut and Veronese, 2012), whereas site-specific PEGylation in the current study resulted in highly homogenous PEGylation as demonstrated by non-reducing SDS-PAGE, barium iodide staining, and MALDI-TOF analysis. Several other sites were identified that could lead to specific and homogenous PEGylation of G-CSF, including the C-terminal unstructured region and the loop between helix C and D. It is important to emphasize that we also identified solvent-accessible sites in the $\mathrm{CD}$ loop region. This region is of particular interest since huG-CSF is O-glycosylation at threonine 133 in the CD loop (Kubota et al., 1990). This glycosylation protects the protein from degradation by proteases like neutrophil elastase (Carter et al., 2004). We believe that PEGylation at these solventaccessible sites in the CD loop will increase biological half-life through imparting resistance to proteases and prevention from renal filtration simultaneously. However, studying the efficiency of these sites for PEGylation and afterward analyzing the effect on the biological activity is beyond the scope of this study. It would be carried out in the future as a separate study. In summary, here we have demonstrated that cysteine could be inserted/substituted at strategically defined solvent-accessible sites in G-CSF to facilitate site-specific PEGylation for the homogenous product with longer and improved in vivo biological activity.

\section{CONCLUSION}

We have successfully designed G-CSF variants for site-specific PEGylation, which may provide a solution toward prolonged half-life and biological activity. The site-specific PEGylated variants were successfully expressed, purified, and characterized. Importantly, the administration of the engineered variant conjugated with $40 \mathrm{kDa}$ PEG leads to improved and longer leukocyte proliferation in neutropenic mice, wherein neutropenia was induced by cyclophosphamide. Even at half the dose, the $40 \mathrm{kDa}$ PEG conjugated G-CSF variant leads to enhanced and longer biological activity in the neutropenia mice model. Consequently, this variant could be administered at a lower dosage than the $20 \mathrm{kDa}$ PEGylated G-CSF while retaining the same therapeutic efficacy. The site-specific higher-molecularweight PEGylated variant also shows promise for the sameday administration of the G-CSF drug, which is a challenge in the current G-CSF therapy regimen in the treatment of chemotherapy-induced neutropenia. These engineered cysteine variants and their derivatives hold promise to become a nextgeneration G-CSF drug.

\section{DATA AVAILABILITY STATEMENT}

The raw data supporting the conclusions of this article will be made available by the authors, without undue reservation.

\section{ETHICS STATEMENT}

The animal study was reviewed and approved by IAEC, CSIRIMTECH.

\section{AUTHOR CONTRIBUTIONS}

SD conceived the study, helped in analysis of data, and wrote the manuscript. MK performed the experiments 
and analyzed the data. GS provided technical and administrative support to the project. He also helped in improving the manuscript. All authors contributed to the article and approved the submitted version.

\section{FUNDING}

SD acknowledges the Department of Biotechnology, Ministry of Science and Technology, Government of India for the DBT BioCARe Fellowship number

\section{REFERENCES}

Anderlini, P., Przepiorka, D., Champlin, R., and Korbling, M. (1996). Biologic and clinical effects of granulocyte colony-stimulating factor in normal individuals. Blood 88, 2819-2825. doi: 10.1182/blood.v88.8.2819.bloodjournal8882819

Aritomi, M., Kunishima, N., Okamoto, T., Kuroki, R., Ota, Y., and Morikawa, K. (1999). Atomic structure of the GCSF-receptor complex showing a new cytokine-receptor recognition scheme. Nature 401, 713-717. doi: 10.1038/ 44394

Arvedson, T., O'Kelly, J., and Yang, B. B. (2015). Design rationale and development approach for pegfilgrastim as a long-acting granulocyte colony-stimulating factor. BioDrugs 29, 185-198. doi: 10.1007/s40259-015-0127-4

Bartel, R. L., Marcelo, C. L., and Voorhees, J. J. (1987). Partial characterization of phospholipase C activity in normal, psoriatic uninvolved, and lesional epidermis. J. Invest. Dermatol. 88, 447-451. doi: 10.1111/1523-1747. ep12469836

Carter, C. R., Whitmore, K. M., and Thorpe, R. (2004). The significance of carbohydrates on G-CSF: differential sensitivity of G-CSFs to human neutrophil elastase degradation. J. Leukoc. Biol. 75, 515-522. doi: 10.1189/jlb.0803378

Chan, A., Fu, W. H., Shih, V., Coyuco, J. C., Tan, S. H., and Ng, R. (2011). Impact of colony-stimulating factors to reduce febrile neutropenic events in breast cancer patients receiving docetaxel plus cyclophosphamide chemotherapy. Support Care Cancer 19, 497-504. doi: 10.1007/s00520-010-0843-8

Chen, X., Bai, Y., Zaro, J. L., and Shen, W. C. (2010). Design of an in vivo cleavable disulfide linker in recombinant fusion proteins. Biotechniques 49, 513-518. doi: $10.2144 / 000113450$

Cox, G. N., Chlipala, E. A., Smith, D. J., Carlson, S. J., Bell, S. J., and Doherty, D. H. (2014). Hematopoietic properties of granulocyte colonystimulating factor/immunoglobulin (G-CSF/IgG-Fc) fusion proteins in normal and neutropenic rodents. PLoS One 9:e91990. doi: 10.1371/journal.pone. 0091990

Crawford, J. (2003). Once-per-cycle pegfilgrastim (Neulasta) for the management of chemotherapy-induced neutropenia. Semin. Oncol. 30, 24-30. doi: 10.1016/ s0093-7754(03)00314-2

Crawford, J., Dale, D. C., and Lyman, G. H. (2004). Chemotherapy-induced neutropenia: risks, consequences, and new directions for its management. Cancer 100, 228-237. doi: 10.1002/cncr.11882

DeFrees, S., Wang, Z. G., Xing, R., Scott, A. E., Wang, J., Zopf, D., et al. (2006). GlycoPEGylation of recombinant therapeutic proteins produced in Escherichia coli. Glycobiology 16, 833-843. doi: 10.1093/glycob/cwl004

Doherty, D. H., Rosendahl, M. S., Smith, D. J., Hughes, J. M., Chlipala, E. A., and Cox, G. N. (2005). Site-specific PEGylation of engineered cysteine analogues of recombinant human granulocyte-macrophage colony-stimulating factor. Bioconjug. Chem. 16, 1291-1298. doi: 10.1021/bc050172r

Dozier, J. K., and Distefano, M. D. (2015). Site-specific PEGylation of therapeutic proteins. Int. J. Mol. Sci. 16, 25831-25864. doi: 10.3390/ijms161025831

El Ouriaghli, F., Fujiwara, H., Melenhorst, J. J., Sconocchia, G., Hensel, N., and Barrett, A. J. (2003). Neutrophil elastase enzymatically antagonizes the in vitro action of G-CSF: implications for the regulation of granulopoiesis. Blood 101, 1752-1758. doi: 10.1182/blood-2002-06-1734

Fidler, K., Jevsevar, S., Milunovic, T., Skrajnar, S., Premzl, A., Kunstelj, M., et al. (2011). The characterization and potential use of G-CSF dimers and their pegylated conjugates. Acta Chim. Slov. 58, 1-8.
BT/BioCARe/01/517/2011-12. The authors also acknowledge the funding from the CSIR-Fast Track Translational project (MLP-011).

\section{ACKNOWLEDGMENTS}

The authors gratefully acknowledge overall support from CSIRIMTECH for providing all in-house infrastructure and facilities, including animal house, DNA sequencing, and MALDI-TOF mass spectrometry.

Halpern, W., Riccobene, T. A., Agostini, H., Baker, K., Stolow, D., Gu, M. L., et al. (2002). Albugranin, a recombinant human granulocyte colony stimulating factor (G-CSF) genetically fused to recombinant human albumin induces prolonged myelopoietic effects in mice and monkeys. Pharm. Res. 19, 17201729.

Ishikawa, M., Iijima, H., Satake-Ishikawa, R., Tsumura, H., Iwamatsu, A., Kadoya, T., et al. (1992). The substitution of cysteine 17 of recombinant human G-CSF with alanine greatly enhanced its stability. Cell Struct. Funct. 17, 61-65. doi: $10.1247 /$ csf.17.61

Kaur, N., Sinha, P. K., and Sahni, G. (2019). Site-specific PEGylation of microplasmin for improved thrombolytic therapy through engineering enhanced resistance against serpin mediated inhibition. PLoS One 14:e0217234. doi: 10. 1371/journal.pone.0217234

Kubota, N., Orita, T., Hattori, K., Oh-eda, M., Ochi, N., and Yamazaki, T. (1990). Structural characterization of natural and recombinant human granulocyte colony-stimulating factors. J. Biochem. 107, 486-492. doi: 10.1093/ oxfordjournals.jbchem.a123072

Kurfurst, M. M. (1992). Detection and molecular weight determination of polyethylene glycol-modified hirudin by staining after sodium dodecyl sulfatepolyacrylamide gel electrophoresis. Anal. Biochem. 200, 244-248. doi: 10.1016/ 0003-2697(92)90460-o

Kuwabara, T., Ishikawa, Y., Kobayashi, H., Kobayashi, S., and Sugiyama, Y. (1995). Renal clearance of a recombinant granulocyte colony-stimulating factor, nartograstim, in rats. Pharm. Res. 12, 1466-1469.

Kuwabara, T., Kobayashi, S., and Sugiyama, Y. (1996). Kinetic analysis of receptormediated endocytosis of G-CSF derivative, nartograstim, in rat bone marrow cells. Am. J. Physiol. 271, E73-E84.

Lyman, G. H. (2006). Risks and consequences of chemotherapy-induced neutropenia. Clin. Cornerstone 8(Suppl. 5), S12-S18.

Lyman, G. H., Michels, S. L., Reynolds, M. W., Barron, R., Tomic, K. S., and Yu, J. (2010). Risk of mortality in patients with cancer who experience febrile neutropenia. Cancer 116, 5555-5563.

Mehta, H. M., Malandra, M., and Corey, S. J. (2015). G-CSF and GM-CSF in Neutropenia. J. Immunol. 195, 1341-1349. doi: 10.4049/jimmunol.1500861

Miyafusa, T., Shibuya, R., Nishima, W., Ohara, R., Yoshida, C., and Honda, S. (2017). Backbone circularization coupled with optimization of connecting segment in effectively improving the stability of granulocyte-colony stimulating factor. ACS Chem. Biol. 12, 2690-2696. doi: 10.1021/acschembio.7b00776

Molineux, G. (2003). Pegylation: engineering improved biopharmaceuticals for oncology. Pharmacotherapy 23, 3S-8S.

Molineux, G. (2004). The design and development of pegfilgrastim (PEGrmetHuG-CSF, Neulasta). Curr. Pharm. Des. 10, 1235-1244. doi: 10.2174/ 1381612043452613

Nemunaitis, J. (1997). A comparative review of colony-stimulating factors. Drugs 54, 709-729. doi: 10.2165/00003495-199754050-00004

Nervi, B., Link, D. C., and DiPersio, J. F. (2006). Cytokines and hematopoietic stem cell mobilization. J. Cell. Biochem. 99, 690-705.

Ng, F., and Tang, B. L. (2013). Sirtuins' modulation of autophagy. J. Cell. Physiol. 228, 2262-2270.

Paige, A. G., Whitcomb, K. L., Liu, J., and Kinstler, O. (1995). Prolonged circulation of recombinant human granulocyte-colony stimulating factor by covalent linkage to albumin through a heterobifunctional polyethylene glycol. Pharm. Res. 12, 1883-1888. 
Pasut, G., and Veronese, F. M. (2009). PEG conjugates in clinical development or use as anticancer agents: an overview. Adv. Drug Deliv. Rev. 61, 1177-1188. doi: 10.1016/j.addr.2009.02.010

Pasut, G., and Veronese, F. M. (2012). State of the art in PEGylation: the great versatility achieved after forty years of research. J. Control. Release 161, 461-472. doi: 10.1016/j.jconrel.2011.10.037

Petersen, B., Petersen, T. N., Andersen, P., Nielsen, M., and Lundegaard, C. (2009). A generic method for assignment of reliability scores applied to solvent accessibility predictions. BMC Struct. Biol. 9:51. doi: 10.1186/1472-68 07-9-51

Pfister, D., and Morbidelli, M. (2014). Process for protein PEGylation. J. Control. Release 180, 134-149.

Rosendahl, M. S., Doherty, D. H., Smith, D. J., Bendele, A. M., and Cox, G. N. (2005). Site-specific protein PEGylation: application to cysteine analogs of recombinant human granulocyte colony-stimulating factor. Bioprocess. Int. 3, 52-60.

Roy, A., Kucukural, A., and Zhang, Y. (2010). I-TASSER: a unified platform for automated protein structure and function prediction. Nat. Protoc. 5, 725-738.

Sawhney, P., Katare, K., and Sahni, G. (2016a). PEGylation of truncated streptokinase leads to formulation of a useful drug with ameliorated attributes. PLoS One 11:e0155831. doi: 10.1371/journal.pone. 0155831

Sawhney, P., Kumar, S., Maheshwari, N., Guleria, S. S., Dhar, N., Kashyap, R., et al. (2016b). Site-specific thiol-mediated pegylation of streptokinase leads to improved properties with clinical potential. Curr. Pharm. Des. 22, 5868-5878. doi: $10.2174 / 1381612822666160204120547$

Scholz, M., Ackermann, M., Engel, C., Emmrich, F., Loeffler, M., and Kamprad, M. (2009). A pharmacokinetic model of filgrastim and pegfilgrastim application in normal mice and those with cyclophosphamide-induced granulocytopaenia. Cell. Prolif. 42, 813-822.

Shekhawat, R., Shah, C. K., Patel, A., Srinivasan, S., Kapoor, P., Patel, S., et al. (2019). Structural similarity, characterization of Poly Ethylene Glycol linkage and identification of product related variants in biosimilar pegfilgrastim. PLoS One 14:e0212622. doi: 10.1371/journal.pone.0212622
Tamada, T., Honjo, E., Maeda, Y., Okamoto, T., Ishibashi, M., Tokunaga, M., et al. (2006). Homodimeric cross-over structure of the human granulocyte colonystimulating factor (GCSF) receptor signaling complex. Proc. Natl. Acad. Sci. U.S.A. 103, 3135-3140.

Veronese, F. M. (2001). Peptide and protein PEGylation: a review of problems and solutions. Biomaterials 22, 405-417. doi: 10.1016/S0142-9612(00)00193-9

Veronese, F. M., Mero, A., Caboi, F., Sergi, M., Marongiu, C., and Pasut, G. (2007). Site-specific pegylation of G-CSF by reversible denaturation. Bioconjug. Chem. 18, 1824-1830. doi: 10.1021/bc070123+

Welte, K., Gabrilove, J., Bronchud, M. H., Platzer, E., and Morstyn, G. (1996). Filgrastim (r-metHuG-CSF): the first 10 years. Blood 88, 1907-1929. doi: 10. 1182/blood.V88.6.1907.bloodjournal8861907

Yamasaki, M., Asano, M., Okabe, M., Morimoto, M., and Yokoo, Y. (1994). Modification of recombinant human granulocyte colony-stimulating factor (rhG-CSF) and its derivative ND 28 with polyethylene glycol. J. Biochem. 115, 814-819. doi: 10.1093/oxfordjournals.jbchem.a124421

Zhai, Y., Zhao, Y., Lei, J., Su, Z., and Ma, G. (2009). Enhanced circulation halflife of site-specific PEGylated rhG-CSF: optimization of PEG molecular weight. J. Biotechnol. 142, 259-266. doi: 10.1016/j.jbiotec.2009.05.012

Zheng, C., Ma, G., and Su, Z. (2007). Native PAGE eliminates the problem of PEG-SDS interaction in SDS-PAGE and provides an alternative to HPLC in characterization of protein PEGylation. Electrophoresis 28, 2801-2807. doi: 10.1002/elps.200600807

Conflict of Interest: The authors declare that the research was conducted in the absence of any commercial or financial relationships that could be construed as a potential conflict of interest.

Copyright (C) 2020 Kumari, Sahni and Datta. This is an open-access article distributed under the terms of the Creative Commons Attribution License (CC BY). The use, distribution or reproduction in other forums is permitted, provided the original author(s) and the copyright owner(s) are credited and that the original publication in this journal is cited, in accordance with accepted academic practice. No use, distribution or reproduction is permitted which does not comply with these terms. 